\title{
Erythromycin breath test predicts oral clearance of cyclosporine in kidney transplant recipients
}

\begin{abstract}
It has been shown recently that cyclosporine is largely metabolized by P450IIIA (CYP3A), an enzyme whose catalytic activity varies significantly among patients. To determine whether heterogeneity in P450IIIA activity contributes to interpatient differences in cyclosporine dosing requirements, the oral pharmacokinetics of the drug were determined in 20 stable kidney transplant recipients. P450IIIA activity was then measured in each patient by use of the erythromycin breath test. In the 16 patients who were at steady state, the logarithm of the apparent oral clearance of cyclosporine correlated significantly with the rate of ${ }^{14} \mathrm{CO}_{2}$ exhaled in breath after intravenous administration of $\left[{ }^{14} \mathrm{C} \mathrm{N}\right.$-methyl]erythromycin $(r=0.55, p=0.03)$. No significant correlations existed between apparent oral clearance and age, high-density lipoprotein cholesterol or low-density lipoprotein cholesterol, or hematocrit in these patients. We conclude that heterogeneity in P450IIIA activity significantly contributes to interpatient differences in dosing requirements of cyclosporine in kidney transplant patients. (Clin Pharmacol Ther $1992 ; 52: 471-8$.)
\end{abstract}

D. Kim Turgeon, MD, Daniel P. Normolle, $\mathrm{PhD}$, Alan B. Leichtman, $\mathrm{MD}$, Thomas M. Annesley, PhD, David E. Smith, PhD, and Paul B. Watkins, MD Ann Arbor, Mich.

Cyclosporine is an immunomodulatory agent commonly administered to patients who have received transplanted organs. The oral dose of cyclosporine required to achieve a target trough blood level varies at least tenfold among patients. ${ }^{1}$ This heterogeneity appears to largely reflect differences in the extent of cyclosporine absorption from the gastrointestinal tract. ${ }^{1,2}$ However, interpatient differences in metabolism of cyclosporine also appear to be important.

Cyclosporine has been shown to be chiefly metabolized in the liver and intestine by an enzyme termed "P450IIIA."3-6 (In this article, the term "P450IIIA" is used to refer to members of the CYP3A gene subfamily. ${ }^{7}$ ) The metabolites produced by P450IIIA are

From the Departments of Medicine, Biostatistics, Clinical Pathology, Upjohn Center for Clinical Pharmacology, and College of Pharmacy, University of Michigan.

Supported by the National Institutes of Health, Bethesda, Md. (grants GM88139 and ES05770 to Dr. Watkins), and the General Clinical Research Center of the University of Michigan (grant MOl-RR00042).

Received for publication April 17, 1992; accepted July 9, 1992. Reprint requests: Paul B. Watkins, MD, General Clinical Research

Center, A7119 University Hospital, University of Michigan Medical Center, Ann Arbor, MI 48109.

13/1/40849 mainly excreted in bile; renal excretion of cyclosporine and its metabolites is negligible. ${ }^{1}$

There are marked interindividual differences in the catalytic activity of P450IIIA. ${ }^{8.9}$ To determine if this heterogeneity partly accounts for interpatient differences in cyclosporine dosing requirements, we recently studied 32 patients who were receiving cyclosporine as an experimental treatment of psoriasis. ${ }^{10}$ Before treatment with the drug was started, each patient's P450IIIA activity was measured by means of the erythromycin breath test. ${ }^{11}$ This test is based on the observations that P450IIIA appears to exclusively catalyze the $N$-demethylation of erythromycin ${ }^{11}$ and that the carbon atom in the removed methyl group should largely appear in the breath as carbon dioxide. ${ }^{12}$ The patient receives an intravenous injection of a trace amount of $\left[{ }^{14} \mathrm{C} \mathrm{N}\right.$-methyl $]$ erythromycin, and the rate of its subsequent demethylation in vivo is estimated from the rate at which the patient produces ${ }^{14} \mathrm{CO}_{2}$ in the breath. We have shown that the findings of the erythromycin breath test correlate well with the liver content of P450IIIA in patients. ${ }^{13}$ In the patients with psoriasis, we found that the interpatient heterogeneity in P450IIIA activity, as measured by the erythromycin breath test, largely accounted for interpatient 
Table 1. Patient characteristics

\begin{tabular}{|c|c|c|c|c|c|c|c|c|}
\hline $\begin{array}{l}\text { Patient } \\
\text { No. }\end{array}$ & Renal disease & $\begin{array}{l}\text { Age } \\
(y r)\end{array}$ & Sex & Vehicle & $\begin{array}{c}\text { ERMBT } \\
\left(\%{ }^{14} \mathrm{C} / \mathrm{hr}\right)\end{array}$ & $\begin{array}{c}\text { Dose } \\
(m g / k g / d a y)\end{array}$ & $\begin{array}{c}\text { Trough } \\
\text { (O-hour } \\
\text { level) }\end{array}$ & $\begin{array}{c}\text { Trough } \\
\text { (24-hour } \\
\text { level) }\end{array}$ \\
\hline $1 *$ & Post-streptococcal glomerulonephritis & 44 & Male & Capsules & 4.22 & 6.430 & 118 & 155 \\
\hline 2 & Post-streptococcal glomerulonephritis & 42 & Male & Liquid & 3.16 & 4.220 & 62 & 57 \\
\hline 3 & Diabetes & 54 & Female & Capsules & 4.16 & 3.980 & 109 & 117 \\
\hline 4 & Alport's syndrome & 31 & Male & Capsules & 4.15 & 3.610 & 57 & 59 \\
\hline 5 & Diabetes & 35 & Male & Capsules & 3.36 & 6.690 & 139 & 134 \\
\hline $6^{*}$ & ESRD, chronic infection & 33 & Male & Capsules & 3.50 & 2.020 & 60 & 89 \\
\hline 7 & Diabetes & 38 & Male & Capsules & 1.62 & 4.130 & 88 & 100 \\
\hline $8^{*}$ & ESRD, unclear cause & 59 & Male & Liquid & 3.20 & 3.480 & 110 & 79 \\
\hline 9 & Polycystic kidney disease & 43 & Male & Capsules & 1.76 & 2.030 & 118 & 91 \\
\hline 10 & Hypertension & 36 & Male & Liquid & 5.59 & 3.125 & 81 & 74 \\
\hline $11 *$ & Lupus & 34 & Female & Liquid & 4.37 & 3.970 & 75 & 124 \\
\hline 12 & Polycystic kidney disease & 42 & Male & Liquid & 3.49 & 4.880 & 95 & 78 \\
\hline 13 & Polycystic kidney disease & 60 & Male & Liquid & 2.36 & 2.680 & 118 & 104 \\
\hline 14 & Wegener's granulomatosis & 21 & Male & Capsules & 3.04 & 5.350 & 124 & 106 \\
\hline 15 & ESRD, unclear cause & 38 & Male & Capsules & 2.60 & 6.330 & 67 & 83 \\
\hline 16 & Polycystic kidney disease & 54 & Female & Liquid & 3.42 & 2.870 & 92 & 79 \\
\hline 17 & Immunoglobulin A nephropathy & 43 & Male & Capsules & 2.49 & 2.700 & 72 & 76 \\
\hline 18 & Medullary cystic disease & 22 & Male & Capsules & 2.17 & 3.190 & 106 & 105 \\
\hline 19 & Lupus & 19 & Female & Liquid & 3.65 & 6.110 & 93 & 71 \\
\hline 20 & Diabetes & 39 & Female & Capsules & 2.08 & 1.920 & 183 & 177 \\
\hline \multirow{2}{*}{\multicolumn{2}{|c|}{$\begin{array}{l}\text { Mean (all patients, } N=20 \text { ) } \\
\text { SD }\end{array}$}} & 35.4 & & & 3.22 & 3.99 & 98.4 & 97.9 \\
\hline & & 11.5 & & & 1.00 & 1.53 & 30.9 & 31.2 \\
\hline \multirow{2}{*}{\multicolumn{2}{|c|}{$\begin{array}{l}\text { Mean (patients analyzed, } n=16 \text { ) } \\
\text { SD }\end{array}$}} & 38.6 & & & 3.07 & 3.99 & 100.3 & 94.4 \\
\hline & & 11.7 & & & 1.04 & 1.51 & 32.2 & 30.4 \\
\hline
\end{tabular}

ERMBT, Erythromycin breath test; ESRD, end-stage renal disease.

*Patients excluded from analysis because they were not at steady state (see Methods section).

differences in the trough blood levels of cyclosporine that were observed after drug administration. ${ }^{10} \mathrm{We}$ concluded that the erythromycin breath test may therefore be useful as a guide in administration of cyclosporine for similar patients.

However, the relevance of our observations to the kidney transplant population was unclear. In contrast to the psoriasis patients studied, kidney transplant recipients often have severe systemic diseases and generally are receiving multiple medications known or suspected to influence P450IIIA activity ${ }^{8.9}$; these factors could significantly influence drug absorption or metabolism. In addition, many investigators believe that the area under the cyclosporine blood concentration-time curve during the dosing interval (AUC) is superior to a simple trough blood level as a predictor of clinical events in kidney transplant recipients. ${ }^{14,15}$ We therefore performed an oral pharmacokinetic study of cyclosporine in 20 stable kidney transplant recipients who also received the erythromycin breath test. Our findings support the idea that interpatient differ- ences in P450IIIA activity contribute to the heterogeneity in cyclosporine dosing requirements observed in this patient population.

\section{METHODS}

Patients studied. Twenty kidney transplant patients were selected for study. At least 6 months had elapsed since kidney transplant surgery in all patients, and all were considered to be medically stable. In addition, each patient had been maintained on the same dose of cyclosporine for at least 1 month, and each took the cyclosporine as a single daily dose. Characteristics of the patients are shown in Table 1 .

Patients who met the above criteria were recruited from the kidney transplant clinic by one of the investigators (D.K.T.). To ensure that the patients tested constituted a representative sample of the transplant population, no consideration was given to cause of kidney failure or to whether the patients had systemic diseases. Three of the patients had received an erythromycin breath test in the past; however, this informa- 
Table II. Medications used by the 16 patients at steady state

\begin{tabular}{|c|c|c|}
\hline & Medications & Patient No. \\
\hline Imunosuppressive agents & $\begin{array}{l}\text { Prednisone } \\
\text { Azathioprine }\end{array}$ & $\begin{array}{l}\text { All patients } \\
\text { All patients except } 10,19 \text {, and } 20\end{array}$ \\
\hline \multicolumn{3}{|l|}{ Antihypertensive agents } \\
\hline Ace inhibitors & Enalapril & 5 \\
\hline$\beta$-Blockers & $\begin{array}{l}\text { Atenolol } \\
\text { Labetalol }\end{array}$ & $\begin{array}{l}9,10,17 \\
14,19\end{array}$ \\
\hline \multicolumn{3}{|l|}{ Calcium channel blockers } \\
\hline & Diltiazem & 9,13 \\
\hline & Nifedipine & $10,12,15$ \\
\hline & Verapamil & $7,18,20$ \\
\hline Diuretic agents & Furosemide & $3,4,5,7,9,12,13,17$ \\
\hline \multirow[t]{4}{*}{ Vasodilators } & Clonidine & $14,17,20$ \\
\hline & Minoxidil & 17 \\
\hline & Prazosin & 9 \\
\hline & Terazosin & 4 \\
\hline \multirow[t]{9}{*}{ Miscellaneous medications } & Acetaminophen & 18 \\
\hline & Docusate sodium & 3,17 \\
\hline & $\begin{array}{l}\text { Combination of aluminum hydroxide, magnesium } \\
\text { hydroxide, and simethicone (Gelusil) }\end{array}$ & 13 \\
\hline & Insulin & $3,5,7,9,20$ \\
\hline & Isotretinoin & 5 \\
\hline & Psyllium hydrophilic mucilloid (Metamucil) & 3 \\
\hline & Metoclopramide & 20 \\
\hline & Multivitamin & 3 \\
\hline & Tetracycline & 2 \\
\hline
\end{tabular}

tion was not considered in patient selection, and the results of the tests were not known by the physicians who prescribed cyclosporine.

To maintain patients at steady state with regard to their cyclosporine dosing while in our General Clinical Research Center, each patient was asked to maintain a detailed dietary history for the 3 days before admission. The diaries were assessed by the General Clinical Research Center nutritionists, and diets matched in fat, protein, and carbohydrate content were administered to the patients during their admission to the unit. In particular, every effort was made to provide the patient with his or her usual breakfast. Each patient was told to take his or her cyclosporine dose in exactly the same fashion as he or she had been administering it at home. Eight of the patients were taking cyclosporine in liquid form; each brought the graduated cylinder, the glass, and the spoon he or she used at home to take the medication. The remaining 12 patients were taking their cyclosporine doses in the gelatin capsule formulation. The liquid and gelatin preparations have been reported to be bioequivalent. ${ }^{16}$

Each patient was admitted to the General Clinical Research Center on the evening before the start of the pharmacokinetic study. Each received dinner, and the following morning each was asked to take the cyclosporine dose at the exact time and in the exact relationship to breakfast as at home. Five-milliliter venous blood samples were withdrawn through a heparin lock at the following times: $0,1 \frac{1}{2}, 1,1 \frac{1}{2}, 2,2 \frac{1}{2}, 3,3 \frac{1}{2}, 4$, $5,6,8,10,12,18$, and 24 hours after oral administration (the 0 -hour sample was obtained immediately before administration).

The erythromycin breath test. The erythromycin breath test was administered, and the findings were calculated as described previously. "The findings are expressed as the percentage of administered carbon 14 that appeared in the breath in 1 hour. The breath test was administered to each patient after the final blood sample was obtained ( 24 hours) but before the next dose of cyclosporine was taken. We have shown that the results of the breath test decrease when patients begin treatment with cyclosporine ${ }^{10}$; this presumably reflects competition between this cyclosporine and erythromycin for metabolism by P450IIIA. However, this decrease in the erythromycin breath test result is small compared with interpatient differences in the results of the test; hence the erythromycin breath test remains a valid means of measuring P450IIIA aciivity in patients receiving cyclosporine. ${ }^{10}$ 

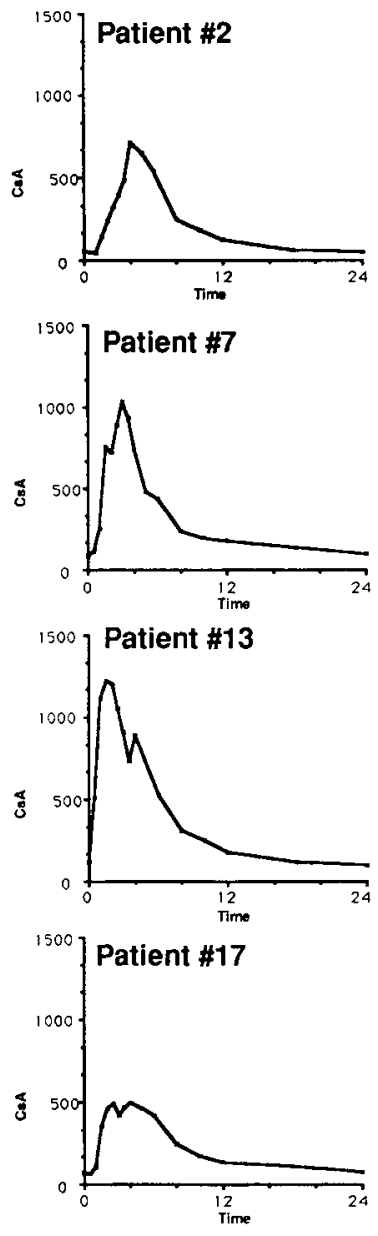
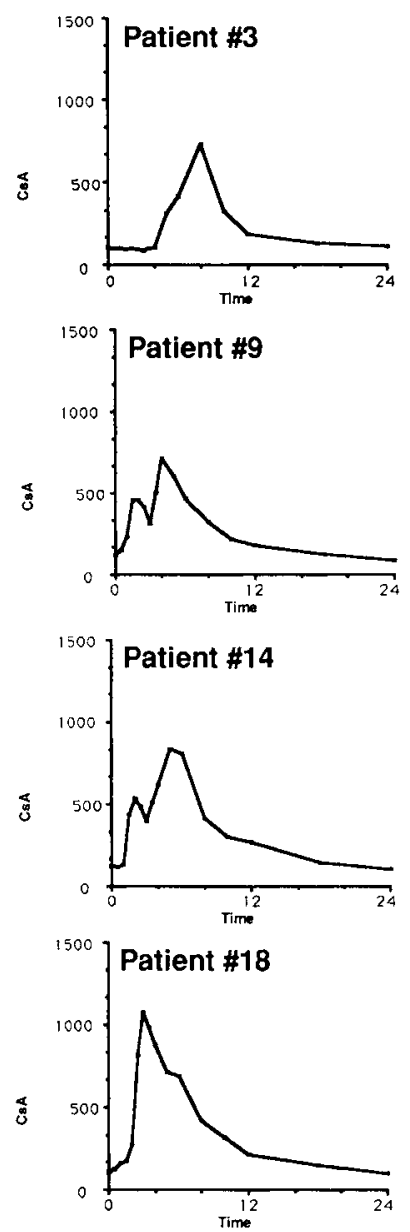
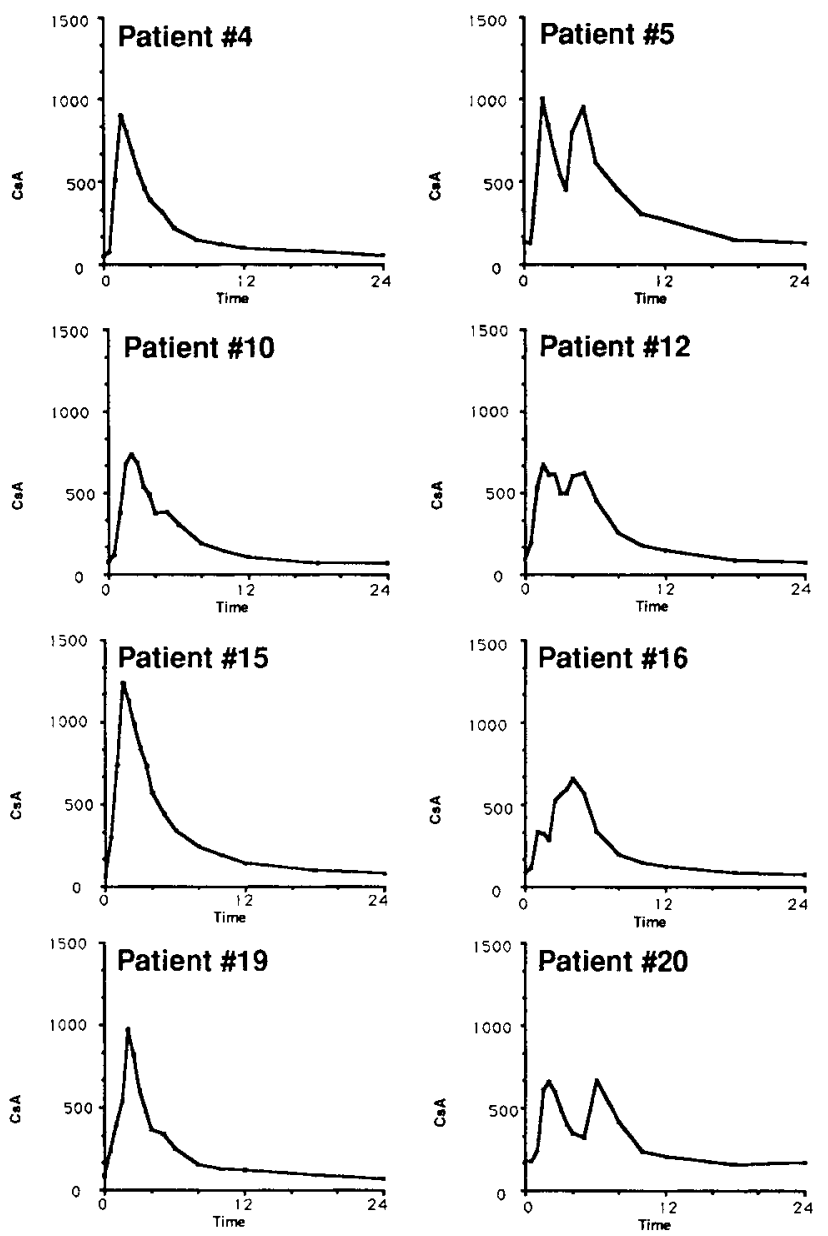

Fig. 1. Cyclosporine (CsA) blood concentration-time profiles in the 16 patients at steady state.

Cyclosporine blood level analysis. Whole blood samples obtained from the patients were refrigerated $\left(4^{\circ} \mathrm{C}\right)$. The concentration of parent cyclosporine in the whole blood was determined by a previously validated HPLC method. ${ }^{17}$ The time interval between blood drawing and blood analysis did not exceed 4 days. Blood samples from a single patient were always tested together.

Additional laboratory studies. Blood hematocrit and serum concentrations of high-density lipoprotein cholesterol, (HDL) and low density lipoprotein (LDL) cholesterol, and total cholesterol were determined by commercial automated systems on blood drawn at the time of the patient was admitted to the General Clinical Research Center.

Pharmacokinetic analyses. Blood concentrationtime profiles of cyclosporine were analyzed at steady state by use of a noncompartmental approach. ${ }^{18}$ The drug half-life $\left(t_{1 / 2}\right)$ was determined by linear regression of the log-linear terminal phase of the curve. The apparent oral clearance $(\mathrm{CL} / F)$ was calculated as the administered dose divided by the AUC, for which AUC was determined by a combination of the trapezoidal and log-trapezoidal rules over the 24-hour dosing interval. The volume of distribution after oral dosing $\left(\mathrm{V}_{\text {area }} / F\right)$ was determined as total oral clearance divided by the log-linear terminal rate-constant $\left(\lambda_{\mathrm{n}}\right)$, where $t_{1 / 2}=0.693 / \lambda_{n}$. The peak blood concentration $\left(\mathrm{C}_{\max }\right)$ and time to peak $\left(\mathrm{t}_{\max }\right)$ were read directly from the blood concentration-time data. The trough blood level $\left(C_{\text {min }}\right)$ was that value 24 hours after oral administration.

Statistical analysis. The strength of the linear relationships between the erythromycin breath test and various pharmacokinetic parameters was assessed with Pearson's product-moment correlation coefficient. Models for explaining variation in the pharmacokinetic parameters were constructed by use of linear re- 
Table III. Pharmacokinetic parameters of oral cyclosporine in the 16 patients at steady state

\begin{tabular}{rrrccrrr}
\hline $\begin{array}{c}\text { Patient } \\
\text { No. }\end{array}$ & $C_{\max }(\mathrm{ng} / \mathrm{ml})$ & $t_{\max }(\mathrm{hr})$ & $\begin{array}{c}A U C \\
(\mu g \cdot h r / L)\end{array}$ & $C L / F(L / h r \cdot k g)$ & $V_{\text {area }} / F(L / k g)$ & $t_{1 / 2}(\mathrm{hr})$ & $C_{\text {min }} \dagger(\mathrm{ng} / \mathrm{ml})$ \\
\hline 2 & 719 & 4.0 & 4777 & 0.883 & 13.5 & 10.6 & 57 \\
3 & 731 & 8.0 & 5331 & 0.747 & 19.4 & 18.0 & 117 \\
4 & 904 & 1.5 & 4587 & 0.787 & 16.4 & 14.4 & 59 \\
5 & 1006 & 1.5 & 8452 & 0.792 & 12.6 & 11.0 & 134 \\
7 & 1039 & 3.0 & 6756 & 0.610 & 11.7 & 13.3 & 100 \\
9 & 714 & 4.0 & 5941 & 0.342 & 6.0 & 12.2 & 91 \\
10 & 740 & 2.0 & 4693 & 0.666 & 14.5 & 15.1 & 74 \\
12 & 680 & 1.5 & 5834 & 0.836 & 13.9 & 11.5 & 78 \\
13 & 1223 & 1.5 & 8392 & 0.319 & 6.9 & 14.9 & 104 \\
14 & 840 & 5.0 & 7484 & 0.715 & 9.0 & 8.8 & 106 \\
15 & 1239 & 1.5 & 6588 & 0.961 & 20.2 & 14.6 & 83 \\
16 & 665 & 4.0 & 4922 & 0.583 & 13.0 & 15.4 & 79 \\
17 & 497 & 4.0 & 4936 & 0.547 & 10.1 & 12.8 & 76 \\
18 & 1079 & 3.0 & 7761 & 0.411 & 6.8 & 11.5 & 105 \\
19 & 974 & 2.0 & 4923 & 1.241 & 24.9 & 13.9 & 71 \\
20 & 676 & 6.0 & 6883 & 0.279 & 12.3 & 30.5 & 177 \\
Mean & 858 & 3.3 & 6141 & 0.670 & 13.2 & 14.3 & 94 \\
SD & 216 & 1.9 & 1355 & 0.260 & 5.2 & 4.9 & 30
\end{tabular}

$\mathrm{C}_{\max }$, Peak blood concentration; $\mathrm{t}_{\max }$, time to $\mathrm{C}_{\max } ; \mathrm{AUC}$, area under the blood concentration-time curve; CL. $/ F$, apparent oral clearance; $\mathrm{V}_{\text {area }} / F$, volume of distribution after oral administration; $\mathrm{t}_{1 / 2}$, half-life; $\mathrm{C}_{\min }$, trough blood level.

*Patients $1,6,8$, and 11 excluded because they were not at steady state (see Methods section).

$+\mathrm{C}_{\min }$ is the 24-hour trough level in Table I.

gression with forward variable selection (PROC REG in SAS with selection option set equal to forward). The common logarithm of the dependent variable was used if it provided a better linear relationship.

\section{RESULTS}

Twenty kidney transplant recipients were admitted to our General Clinical Research Center for the pharmacokinetic study. In four patients (patients $1,6,8$, 11; Table I) the initial predose blood level (through 0 -hour level) and the blood level obtained at the end of the dosing interval 24 hours later (through 24-hour level) differed by more than $25 \%$. These patients were not considered to be at steady state, and their data were not included in the analysis. Medications that the remaining 16 patients were receiving at the time of the study are summarized in Table II.

P450IIIA activity, as measured by the erythromycin breath test, varied approximately fourfold among the patients (Table I). There was also substantial interpatient variability in the blood concentration-time profiles and derived pharmacokinetic parameters (Fig. 1 and Table III). Double peaks were observed in approximately half of the patients studied (patients 5,9 , $12,13,14,16,17$, and 20) as has been reported previously. ${ }^{2,19,20}$ Absorption of drug appeared to begin within 1 hour after administration in most patients; however, one patient (patient 3; Fig. 1) did not appear to begin absorption of drug until more than 4 hours after administration. This patient was known to have diabetic gastroparesis.

The $t_{\max }$ ranged from $1 \frac{1 / 2}{2}$ to 8 hours. There was also large interpatient heterogeneity in the $\mathrm{C}_{\text {max }}$ and $\mathrm{C}_{\min }$ levels of cyclosporine and the AUC of the drug, $\mathrm{CL} / F, \mathrm{~V}_{\text {area }} / F$, and drug $t_{y_{2}}$ (Table III).

The aim of our study was to determine whether the P450IIIA activity of a patient, as determined by the erythromycin breath test (percentage administered ${ }^{14} \mathrm{C}$ exhaled per hour), correlated with pharmacokinetic parameters that are believed to be important determinants of a patient's dosing requirement of cyclosporine. The most important single parameter in this regard should be the $\mathrm{CL} / F$ of cyclosporine. This term is calculated as the dose of cyclosporine administered divided by the AUC. The "clearance" calculated in this way is "apparent" because it represents the multiple contributions of variations in oral absorption, presystemic metabolism in the gastrointestinal tract and liver, and the systemic elimination of drug. We found that the logarithm of the CL/F (Table III), was significantly correlated with the erythromycin breath test result $(r=0.545, p=0.03$; Fig. 2$)$. The logarithm of the $\mathrm{CL} / F$ did not significantly correlate with patient age (years), blood hematocrit (\%), or blood concentra- 


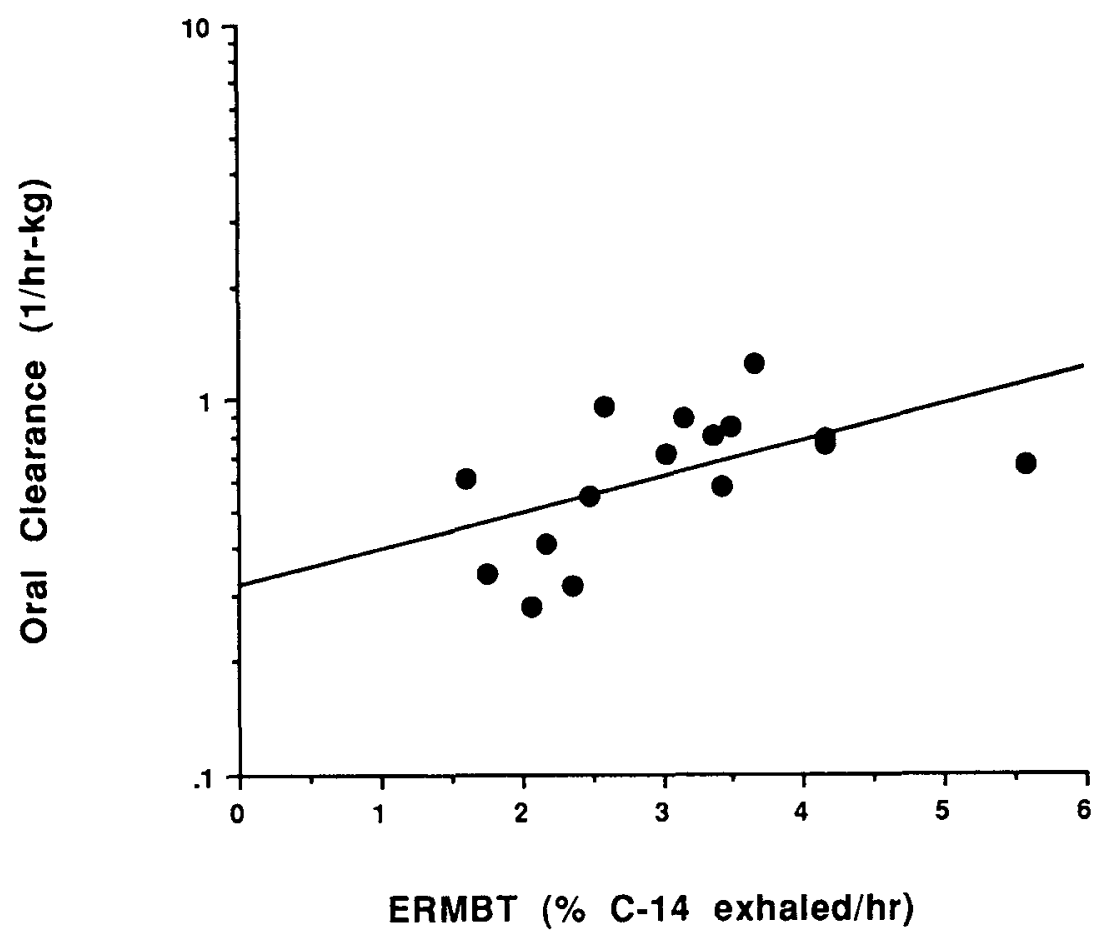

Fig. 2. Correlation between oral clearance and the erythromycin breath test (ERMBT) results in the 16 patients at steady state. The oral clearance values were determined for each patient as the daily dose of cyclosporine received divided by the area under the blood concentration-time curve.

tions of HDL or LDL cholesterol (in milligrams per deciliter; $p>0.10$; data not shown).

We next used multiple regression to create a mathematical model capable of accounting for interpatient variation in $\mathrm{CL} / F$ (dependent variable) based on the patients' erythromycin breath test results, cyclosporine doses, ages, blood hematocrit levels, and concentrations of HDL and LDL cholesterol (independent variables). In the resulting linear model (not shown), the predictive capacity of the erythromycin breath test result remained significant $(p=0.04)$. However, none of the other independent variables had significant predictive capacity $(p>0.10)$, and the model explained approximately one half of the variability in $\mathrm{CL} / F$ values observed $\left(R^{2}=0.48\right)$.

The erythromycin breath test results correlated negatively with the logarithm of the AUC, and the correlation was significant $(r=-0.55, p=0.03$; data not shown). This indicates that patients with higher P450IIIA activity generally had lower AUC values. However, there were no significant correlations between the logarithm of the AUC and the daily dose of cyclosporine, patient age, blood hematocrit, or blood concentrations of HDL or LDL cholesterol $(p>$ $0.10)$.
There was also a negative correlation between the erythromycin breath test and the $\mathrm{C}_{\text {min }}$ (Table III), but this was not significant $(r=-0.37, p=0.17)$. The erythromycin breath test did not significantly correlate with any of the other pharmacokinetic parameters of cyclosporine shown in Table III, including $\mathrm{C}_{\max }$, or the estimated blood $t_{1 / 2}$ of the drug. Neither $C_{\max }$ nor $t_{1 / 2}$ correlated with dose of drug received, patient age, blood hematocrit, or blood concentrations of HDL or LDL cholesterol.

\section{DISCUSSION}

Our previous study ${ }^{10}$ performed in relatively healthy patients suggested that interpatient differences in P450IIIA activity, which are well established, ${ }^{8,9}$ may account in part for interpatient differences in the dosing requirements of cyclosporine. The findings of our current study suggest that this is also the case in kidney transplant recipients. We found that the erythromycin breath test result, which selectively measures P450IIIA catalytic activity, ${ }^{11,13}$ significantly correlated with $\mathrm{CL} / F$ of cyclosporine (Fig. 2). The correlation was positive, consistent with the idea that patients with high P450IIIA activity require larger cyclosporine doses to attain a given target AUC (Fig. 2). The 
variation in $\mathrm{CL} / F$ that was not attributable to heterogeneity in P450IIIA activity may largely reflect variability in oral absorption of drug, because this cannot be distinguished from true clearance in an oral pharmacokinetic study.

Our observations have implications toward understanding previously reported drug interactions involving cyclosporine in kidney transplant recipients. Many drugs reported to increase or decrease blood levels of cyclosporine appear to be inhibitors or inducers, respectively, of P450IIIA. ${ }^{3,21,22}$ The fact that P450IIIA activity appeared to influence apparent oral clearance over the range of activities observed in our transplant recipients supports the hypothesis that up- or downregulation of P450IIIA activity could explain most clinically important drug interactions involving cyclosporine. ${ }^{3,4,10,21}$

We did not find correlations between the $\mathrm{CL} / F$ and any of the other patient characteristics examined. In our larger study of patients receiving cyclosporine for treatment for psoriasis, ${ }^{10}$ we found a correlation between cyclosporine trough blood levels $\left(\mathrm{C}_{\min }\right)$ and patient age and this has been reported by others. ${ }^{23}$ However, this correlation was weak compared with that between the $\mathrm{C}_{\min }$ and the erythromycin breath test results ${ }^{10}$; our failure to find an age correlation may therefore reflect the relatively small sample size in the current study. Cyclosporine is also known to be extensively bound to red cells and to lipoproteins in blood. ${ }^{1}$ However, we found no significant correlations between the $\mathrm{CL} / F$ results and blood hematocrit or blood concentrations of HDL or LDL cholesterol; this is consistent with our earlier observations. ${ }^{10}$

We also found that the erythromycin breath test result was negatively correlated with both the AUC during the dosing interval and with the $\mathrm{C}_{\min }$ of cyclosporine. However, unlike our previous study in patients with psoriasis, ${ }^{10}$ the correlation between the erythromycin breath test results and $\mathrm{C}_{\min }$ did not attain significance in the kidney transplant recipients. This likely reflects the fact that $C_{\min }$ levels varied only 2.5 -fold in the transplant population studied (Table III); the chosen sample size of 20 would be insufficient to reject the null hypothesis. The narrow range of trough levels reflects the fact that the physicians adjusted the daily dose of cyclosporine to achieve blood levels within a target range in the transplant recipients. In contrast, the patients with psoriasis that we studied previously were randomly assigned doses of cyclosporine and their $\mathrm{C}_{\min }$ values varied almost eightfold. ${ }^{10}$ The effect of the relatively narrow range of $\mathrm{C}_{\min }$ probably ac- counts for our inability to find a correlation between drug dose and $\mathrm{C}_{\text {min }}$.

The erythromycin breath test result also did not correlate with either cyclosporine $\mathrm{C}_{\max }$ or our estimate of blood $t_{1 / 2}$ of the drug. This probably indicates that $\mathrm{C}_{\max }$ is largely determined by the absorption pharmacokinetics (i.e., rate and time lags) and that the $t_{1 / 2}$ we estimated is a function of drug distribution and elimination.

In summary, the erythromycin breath test result was the only variable we examined that correlated with the $\mathrm{CL} / F$ of cyclosporine in our kidney transplant recipients. Our data support a primary role of P450IIIA in drug interactions that involve cyclosporine in kidney transplant recipients. Moreover, our observations suggest that the erythromycin breath test may be useful in estimation of appropriate dosing of cyclosporine in this patient population.

\section{References}

1. Kahan BD. Cyclosporine. N Engl J Med 1989;321:172538.

2. Lindholm A, Henricsson S, Lind M, Dahlquist R. Intraindividual variability in the relative systemic availability of cyclosporin after oral dosing. Eur J Clin Pharmacol 1988;34:461-4.

3. Kronbach T, Fischer V, Meyer UA. Cyclosporine metabolism in human liver: identification of a cytochrome P-450III gene family as the major cyclosporine-metabolizing enzyme explains interactions of cyclosporine with other drugs. Clin Pharmacol. Ther 1988;43:630-5.

4. Combalbert J, Fabre I, Fabre G, et al. Metabolism of cyclosporin A: IV. Purification and identification of the rifampicin-inducible human liver cytochrome P-450 (cyclosporin A oxidase) as a product of P450IIIA gene subfamily. Drug Metab Dispos 1989;17:197-207.

5. Kolars JC, Awni WM, Merion RM, Watkins PB. Firstpass metabolism of cyclosporin by the gut. Lancet 1991;338:1488-90.

6. Kolars JC, Stetson PL, Rush BD, et al. Cyclosporin metabolism by P450IIIA in rat enterocytes-another determinant of oral bioavailability? Transplantation 1992;53:596-602.

7. Nebert DW, Nelson DR, Coon MJ, et al. The P450 superfamily: update on new sequences, gene mapping, and recommended nomenclature. DNA Cell Biol 1991; 10:1-14.

8. Watkins PB. Role of cytochromes $\mathrm{P} 450$ in drug metabolism and hepatotoxicity. Semin Liver Dis 1990; $10: 235-50$.

9. Guengerich FP. Characterization of human microsomal cytochrome P-450 enzymes. Annu Rev Pharmacol Toxicol 1989;29:241-64.

10. Watkins PB, Hamilton TA, Annesley TM, Ellis CN, 
Kolars JC, Voorhees JJ. The erythromycin breath test as a predictor of cyclosporine blood levels. CLIN PHARMACOL THER 1990;48:120-9.

11. Watkins PB, Murray SA, Winkelman LG, Heuman DM, Wrighton SA, Guzelian PS. Erythromycin breath test as an assay of glucocorticoid-inducible liver cytochromes P-450. J Clin Invest 1989;83:688-97.

12. Baker AL, Kotake AN, Schoeller DA. Clinical utility of breath tests for the assessment of hepatic function. Semin Liver Dis 1983;3:318-29.

13. Lown K, Kolars J, Turgeon DK, Merion R, Wrighton SA, Watkins PB. The erythromycin breath test selectively measures P450IIIA in patients with severe liver disease. Clin Pharmacol Ther 1992;51:229-38.

14. Grevel J, Kahan BD. Area under the curve monitoring of cyclosporine therapy: the early posttransplant period. Ther Drug Monit 1991;13:89-95.

15. Kasiske BL, Heim-Duthoy K, Rao KV, Awni WM. The relationship between cyclosporine pharmacokinetic parameters and subsequent acute rejection in renal transplant recipients. Transplantation 1988;46:716-22.

16. Nashan B, Bleck J, Wonigeit K, et al. Effect of the application form of cyclosporine on blood levels: comparison of oral solution and capsules. Transplant Proc 1988;20:637-9.
17. Annesley T, Matz K, Balogh L, Clayton L, Giacherio D. Liquid-chromatographic analysis for cyclosporine with use of a microbore column and small sample volume. Clin Chem 1986;32:1407-9.

18. Gibaldi M, Perrier D. Pharmacokinetics. 2nd ed. New York: Marcel Dekker, 1982:199-219, 409-16.

19. Gupta SK, Benet LZ. Absorption kinetics of cyclosporine in healthy volunteers. Biopharm Drug Dispos 1989;10:591-6.

20. Phillips TM, Karmi SA, Frantz SC, Henriques HF. Absorption profiles of renal allograft recipients receiving oral doses of cyclosporine: a pharmacokinetic study. Transplant Proc 1988;20,2:457-61.

21. Pichard L, Fabre I, Fabre G, et al. Cyclosporin A drug interactions: screening for inducers and inhibitors of cytochrome P450 (cyclosporin A oxidase) in primary cultures of human hepatocytes and in liver microsomes. Drug Metab Dispos 1990;18:595-606.

22. Watkins PB. The role of cytochromes P-450 in cyclosporine metabolism. J Am Acad Dermatol 1990;23:1301-11.

23. Rodighiero V. Therapeutic drug monitoring of cyclosporin: practical applications and limitations. Clin Pharmacokinet 1989;16:27-37.

\section{Bound volumes available to subscribers}

Bound volumes of Clinical Pharmacology \& Therapeutics are available to subscribers (only) for the 1992 issues from the Publisher, at a cost of $\$ 51.00$ for domestic, $\$ 67.57$ for Canadian, and $\$ 64.00$ for international subscribers for Vol. 51 (January-June) and Vol. 52 (July-December). Shipping charges are included. Each bound volume contains a subject and author index and all advertising is removed. Copies are shipped within 60 days after publication of the last issue of the volume. The binding is durable buckram with the journal name, volume number, and year stamped in gold on the spine. Payment must accompany all orders. Contact Mosby-Year Book, Inc., Subscription Services, 11830 Westline Industrial Drive, St. Louis, MO 63146-3318, USA; phone (800)325-4177, ext. 4351, or (314)453-4351.

Subscriptions must be in force to qualify. Bound volumes are not available in place of a regular journal subscription. 